\title{
Human Versus Nonhuman: Binary Opposition As an Ordering Principle of Western Human Thought
}

\section{Maxine Sheets-Johnstone University of Oregon}

Editors' Note: This paper by Professor Sheets-Johnstone and the response by Professor Menta were presented at the Pacific Division meetings of the Society for the Study of Ethics and Animals, held in Seattle, April 1996.

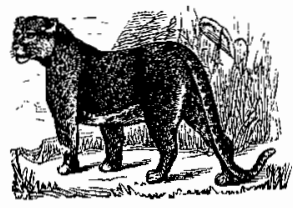

Although they have a long Western history, philosophical and otherwise, binary oppositions are not by any means endemic to the Western world. They are pan-cultural phenomena. The purpose of this paper, however, is to examine a fundamental binary opposition that, in its mode of expression in Western culture, is endemic: the human/nonhuman opposition. Its indigenous signature is readily apparent in the fact that it subsumes other oppositions basic to Western ways of thinking. Subsumed in its compass are the oppositions nature/culture, mind/body, thinking/doing, reason/ emotion. Subsumed also are subsidiary oppositions, ones having to do generally with behavior or behavioral capability ascriptions such as learned/instinctual, future planning/immediate action, articulate/mute, and the like. Following a brief historical introduction, what the examination will show first, in a quite summary way, is how the subsumption works; what it will show second is how the fundamental binary opposition is an ordering principle of thought that is inconsistently applied and that disregards a basic tenet of evolutionary theory; what it will show third is how the categorical and uneven opposition is evidentially unsound, myopically self-serving, and for philosophers especially, a particularly thin justification for cherishing their species.

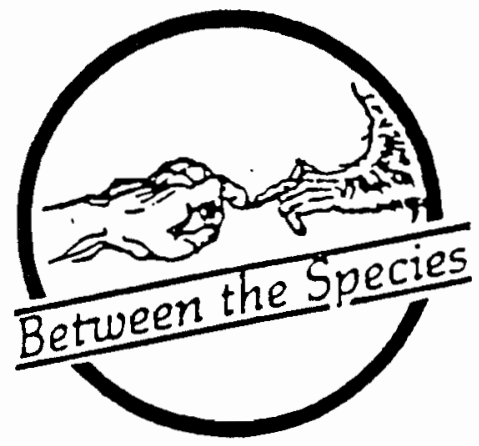

I

To set the notion of binary opposition in brief historical perspective and to clarify the nature of the opposition in question, we can recall Aristotle's specification of four senses of the term "opposite":

1. one thing may be correlatively opposed to something else, as the knower is to the known;

2. one thing may be the contrary of another, as odd is to even, though intermediates between extremes may obtain, as in the contraries "good" and "bad";

3. one term can signify a deficiency or privation in reference to something naturally possessed, as blindness in relation to sight;

4. statements may oppose one another by affirming one thing true and its opposite false, as in "he is human"/"he is nonhuman."

The particular kind of opposition of moment here is of both the second and fourth kind: the second kind in that the oppositional distinction sets up contrasting conceptual categories with no intermediates, the fourth kind in that the oppositional distinction in propositional form affirms truth and falsity. Thus, one is either human or nonhuman; there are no in-betweens and a statement to one effect-"they are human" or "they are nonhuman"--entails the falsity of its opposite. Similarly

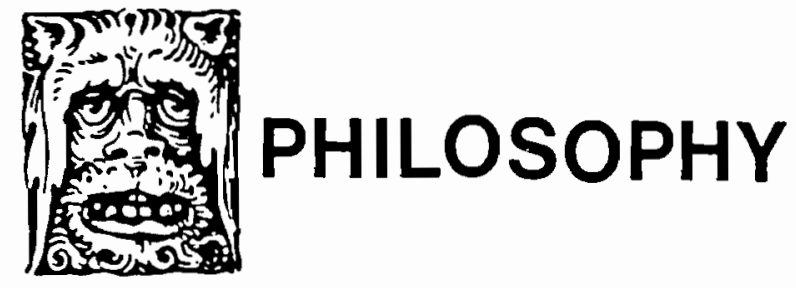


with the other oppositions. Here too there are no in-betweens, and a statement affirming the one of any pair is a denial of its opposite.

According to Western doctrine, humans are distinguished by their culture, their minds, their reasoning, and their thinking, nonhumans by the conceptual antithesis of each of these categories. It is not that humans do not have anything natural about them, that they do not have bodies, that they do not have capabilities to do as well as to think, that they do not have emotions; it is that in the axiological scheme of the four oppositions, these commonly conceived possessions are of inestimably lesser significance and value than their opposites. Indeed, they would not in any preeminent sense be characterized as the natural possessions of humans. Culture, mind, thinking, and reasoning are the natural possessions of humans, just as nature, body, doing, and emotion are the natural possessions of nonhumans. The same axiological scheme obtains in binary oppositions having to do with behavioral ascriptions. It is humans who, in virtue of their humanness, are capable of planning ahead, for example; it is they who devise strategies for the future and who do not live simply in the moment. In contrast, it is nonhumans who are present-oriented, who grab whatever is at hand, and who, "if something starts hurting," as Dennett puts it, "'know enough' to withdraw, but that is the best they can do."2 Not only are the lines clearly drawn to begin with, but they are clearly drawn successively along a considerable number of binary oppositions following upon the first. In effect, to be human is to occupy an invariably privileged, not to say exalted, position in a world of otherwise merely nonhuman creatures. In turn, a "hallowed gap"- to borrow a phrase from Richard Dawkins-is forged in the spectrum of animate life. ${ }^{3}$

\section{II}

Evolutionary theory is based on an abundance of evidence showing historical continuities among creatures all the way from species similarities-e.g., all hominids are consistently bipedal - to phylum similarities-e.g., all creatures who have backbones (fish, amphibians, reptiles, avians, mammals) belong to the phylum "Chordata." Such continuities demand careful attention with respect to the human/nonhuman opposition, and this for two reasons in particular that will be considered here. The first of these concerns the fact that although all humans are hominids, not all hominids are human. Many of our direct hominid ancestors, individuals belonging to the genus Homo, made stone tools and/ or buried their dead. Not belonging to either the species Homo sapiens or Homo sapiens sapiens, however, they were nonhuman. How are we to view them within the fundamental human/ nonhuman opposition? How can we possibly fit them within one or the other category? Moreover, how do we apportion them "mental credit" in terms of culture, mind, thinking, and reasoning? If the answer is "On the basis of behaviors attested to by fossil and artifactual remains," the answer is defective. It is defective because the categorical standards are inconsistently applied. Culture, mind, thinking, and reasoning are commonly honorific epithets reserved for humans and apportioned in miserly fashion, if at all, outside a human circle. They are thus not commonly awarded on the basis of such specific nonhuman practices as termite fishing, the Tanzsprache, hand-clasp-grooming, nest cleanliness, bower-building, or the washing of sweet potatoes. ${ }^{4}$ If they are not awarded to chimpanzees who fashion sticks for digging out termites, honeybees who kinetically transcribe direction with respect to the sun into gravity with respect to a hive, and so on, then on what grounds should they be awarded to nonhuman hominid makers of stone tools or to nonhuman hominids who buried their dead? Simply on the grounds that we know what species those creatures evolved into? If so, then it is sheer favoritism that justifies the ascriptions, a favoritism which, even if not sheer, hardly serves as a valid justification. In particular, even if bolstered by something like a sociobiological explanation that declares the exclusivity of the epithets justified on the basis of adaptation-our genes lead us conceptually to protect and privilege our own kind, hence to protect and privilege those who passed on their genes in a comparatively direct manner to us - the favoritism is little more than a convenient sanctioning device, to be applied whenever and wherever humans are called upon to justify the morality of their interspecies behaviors. Such selective affirmations and denigrations of evolutionary relationships guarantee an ever-ready ladder of evolutionary life with humans at the top. "[T]he traditional summum bonum of bigger brains"5 dominates all from on high, even though, as Stephen Jay Gould has pointed out, the world of living creatures has been, is, and probably always will be, most properly characterized as The Age of Bacteria. ${ }^{6}$ 
There is a further inconsistency in pointing to the archaeological record to determine how mental credit should be apportioned, but an inconsistency of a quite different kind insofar as the treasured epithets are withheld from ascription to some hominids even while they are awarded to others who lived both earlier and later. Mental acuities thus appear, disappear, and then reappear in the course of hominid evolution. In particular, Neandertals are viewed by some paleoanthropologists as thoroughly nonhuman, that is, as lacking the positively valorized natural intelligence of hominids up to that point in time. Homo habilis, the first stone tool-making hominid species, for example, and even earlier, Australopithecus afarensis, the first bipedal hominid species, are both regularly lauded and cherished by all paleoanthropologists as our ancestors precisely on the grounds of their revolutionary new practices, practices mentally credited in such estimable ways as "being able to see to greater distances," "freeing the hands for tool-making," "replacing teeth with tools," and the like. We shall turn to the inconsistent judgment of Neandertals in more detail after considering the second reason for taking evolutionary continuities seriously.

Evolutionary theory teaches that nothing de novo arises in nature. Accordingly, culture, mind, thinking, and reasoning did not suddenly arrive on the scene deus ex machina; they evolved. Though Darwin's insistence on the evolution of mental powers, thus on mental continuities, goes virtually unacknowledged (and virtually uncontested in any scholarly sense, whether because of ignorance of his writings or neglect of the pertinent sources), there is no doubt but that his notion of evolution was wholistic: not merely physical bodies evolved; intact creatures-"persistent wholes"evolved. ${ }^{7}$ Hence Darwin's forthright concern with mental powers-with attention, reasoning, memory, curiosity, imitation, and so on, and their evolution. Received Western wisdom that insists humans are thoroughly unique in virtue of their cultures, their minds, their thinking, and their reasoning insists on discontinuities and feeds in some instances on peculiar evolutionary ideas, indeed at times with the result that humanness appears so special it exceeds the bounds of a natural history. Thus in present-day philosophical literature, we find the idea that humanness was a matter of "one or two mutant neryous systems" having "higher-order capacities" that "would have proliferated like crazy." Now of course there is no doubt that mutations exist in nature; but there is also no doubt that they are usually detrimental if not lethal. As one commonly used biology text points out, "This is not surprising. If one were to change a word at random in a Shakespearean sonnet or a wire at random in a television set, an improvement would be unlikely, and the results might well be disastrous." 9 of the types of mutation known, moreover, additions (and deletions) are the most harmful. ${ }^{10}$ Taken seriously nonetheless, the idea that human minds were produced by "a few mutations... that would enhance... reproductive fitness"ll severs at a stroke any ties that might bind humans and their culture, minds, thinking, or reasoning to other creatures; it cuts humans off from the rest of the animate world. In short, "higher-order capacities" are not viewed as having any substantive evolutionary i.e., historical, relationship to (whatever might be said to constitute) "lower-order capacities. "Higher-order capacities owe their existence not to evolution-to descent with modification" 12 -but to "one or two mutant nervous systems." With these one or two mutant systems, a Rubicon is crossed, and lo! what is essentially nonhuman becomes essentially human.

\section{III}

For the past years, a controversy has been growing as to how modern-day humans are related to Neandertals. Did they replace Neandertals, or are Neandertals the direct ancestor of humans of European and Western Asian descent? In other words, did modern humans arise "out of Africa" and in time spread from there all over the world, overcoming Neandertals in the process, or did they evolve multi-regionally from the stock of hominids already existing multi-regionally, hominids such as Neandertals in Europe and Western Asia? The interest in the question for a philosopher lies not in helping paleoanthropologists sort out their thinking on the matter, ${ }^{13}$ though in one area some clarification-not of necessity demanding the skills of a philosopher-is certainly required. ${ }^{14}$ The interest lies rather in the opportunity to inform oneself of two major and obviously related liabilities in making evolutionary claims: an evolutionarily unenlightened predilection for taking the human/ nonhuman opposition to be categorically absolute; and a predilection for evolutionarily untenable mind-pops-suddenly-into-place scenarios. Each of these liabilities can be succinctly illustrated by considering one well-known stand on the controversy. 
When British paleoanthropologist Christopher Stringer and archaeologist Clive Gamble argue for the replacement theory-early modern humans supplanted Neandertals with no interbreeding - they do so in terms of there being a sudden onset of "symbolic behaviour," a "flick of the switch." 15 Prior to the flick, there was no symbolic behavior but only the mindless repetition of behavioral forms. "The Ancients" (Neandertals) are thus distinguished from "the Moderns" (Homo sapiens) by their lack of culture, mind, thinking, and reasoning. While the distinction might seem to vindicate the existence of a Rubicon since it is offered by evolutionary scientists, it does not. Stringer and Gamble are precisely unaware of symbolic behavior documented in primate species other than humans, let alone aware of any unresolved debate about whether the Tanzsprache is a form of symbolic behavior or of the idea that corporeal representation is a biological matrix. ${ }^{16}$ Their judgment about Neandertals' lack of "symbolic behaviour" is summed up in their statement concerning a "capacity for emulation, for change, but not for symbolism." They say first that, "while they [Neandertals] could emulate they could not fully understand," and then immediately add that "We suspect, for example, that the structures at Molodova and Arcy-sur-Cure more resembled 'nests' than the symbolic 'homes' of the Moderns at Kostenki or Dolni Vestonice." ${ }^{17}$ Their derisive, clearly nonhuman judgment of Neandertal dwellings (and tools) more or less matches their derisive, nonhuman judgment of Neandertal language. ${ }^{18}$ In brief, whatever the Neandertals did, it lacked any sign of the "mental essence"19 that is the ne plus ultra of humanness.

To chart an absolute divide between humans and nonhumans as Stringer and Gamble do is evidentially unsound both because it affirms a Rubicon and thus denies evolutionary continuities and because, as noted above, it ignores evidence of culture, mind, thinking, and reasoning in nonhuman animals. This evidence may be summarized as follows:

Culture: Primatologist W. C. McGrew addresses the question critically and in detail of whether chimpanzees have culture. He uses grooming behavior as a model, consulting two longitudinally studied East African chimpanzee groups (living in Kasoje and Gombe, respectively) that are genetically undifferentiated from each other. He points out that the particular and unusual style of grooming - the grooming-hand-clasp-that is typical for the one group of chimpanzees is totally absent in the other group. After examining possible explanations on the grounds of different environmental selection pressures - parasite infestation, for exampleand after detailed further investigations with respect to criteria for culture, he states:

Suppose that the grooming-hand-clasp had been described by someone like E. T. Hall for a human society in East Africa. Suppose that he presented ethnographic data exactly as here, contrasting the gestural repertoires of two neighboring cultures. It would be accorded cultural status without questioning, and would dutifully be coded into the Human Relations Area File [an ongoing, world-wide research index of every human behavior, belief, practice, ritual, etc. recorded and studied by anthropologists] to be used in future crosscultural analyses. Where does this leave the chimpanzees of Kasoje and Kanyawara [the only other group of chimpanzees observed to practice hand-clasp grooming, but not studied longitudinally] $?^{20}$

Mind: Kanzi is a chimpanzee who comprehends spoken English at the level of a $21 / 2$ year old human child. ${ }^{21}$ He learned English spontaneously when, for the first two-and-a-half years of his life, he observed experimenters attempting to teach English to his mother, who was unable to comprehend the symbols used to teach the language. His comprehension is of particular interest in light of more than 40 years of research on human speech perception which shows it to be dependent upon speech production. ${ }^{22}$ The linkage is causatively explained in terms of "an analogue of the production process-an internal, innately specified vocal-tract synthesizer... that incorporates complete information about the anatomical and physiological characteristics of the vocal tract and also about the articulatory and acoustic consequences of linguistically significant gestures." ${ }^{23}$ In short, a "language module" in the brain decodes the speaker's speech and in fact distinguishes linguistically significant gestures from non-linguistic ones. Clearly, Kanzi does not have "an internal, innately specified vocal-tract synthesizer... that incorporates complete information about the anatomical and physiological characteristic of the vocal tract" since not only does he not have a human brain, 
he does not have a human body, i.e., a human anatomy and physiology. The question of how it is he learned to comprehend normal English sentences on the order of "Get your ball" or even "Put the lemon in the water" and quite outlandish sentences on the order of "Can you throw a potato at the turtle?"24 must thus look to quite other understandings of his abilities. For those understandings to be consistent with standard understandings, one must of course take into account that by common everyday human standards, whoever comprehends a verbal language is ipso facto accorded a mind.

Thinking:25 Zoologist's Bernd Heinrich's experimental study of ravens shows them capable of solving a complicated food procurement problem, thus, as would typically be said of humans, capable of thinking. The ravens determined how a piece of meat that was attached to a twenty-five inch long string attached to their perch could be secured. As Heinrich observes, "to obtain the meat a bird would have to land on the perch above it, reach down with its bill, pull up a loop of string, step onto the string to anchor it, release the bill, reach down again to pull up another loop, and so on, in a repeating cycle of more than twenty steps until the meat was raised to the perch." ${ }^{26}$ What Heinrich found was that after approximately six hours, without any trial and error attempts. but with repeated glances at the meat "as though studying the situation," 27 the ravens secured the meat. Heinrich's conclusion: ravens are intelligent and capable of insight.

Reasoning: Sextus Empiricus cites Chrysippus's account of a dog that, "arriving at a spot where three ways meet, after smelling at the two roads by which the quarry did not pass,... rushes off at once by the third without stopping to smell."28 This same kind of "implicit reasoning" ${ }^{9}$ is twice described by Darwin, once with respect to a retriever who could not carry back two birds at the same time, so killed one, took the first back, then returned for the second dead one..$^{30}$ In the course of giving concrete examples of reasoning in nonhuman animals, Darwin cites the aphorism of South American muleteers to the effect that " "I will not give you the mule whose step is easiest, but la mas racional-the one that reasons best." Interestingly enough, he goes on immediately to cite A. von Humboldt's comment on the muleteers' aphorism: " " [T]his popular expression, dictated by long experience, combats the system of animated machines, better perhaps than all the arguments of speculative philosophy'" (italics added). ${ }^{31}$ Again, interestingly enough, Darwin points out that "Few persons any longer dispute that animals possess some power of reasoning" and notes by way of example that "Animals may constantly be seen to pause, deliberate, and resolve." He then makes the thought-provoking observation that "It is a significant fact, that the more the habits of any particular animal are studied by a naturalist, the more he attributes to reason and the less to unlearnt instincts." 32 (We might recall in this context that Lamarck is judged to have failed to arrive at the principle of natural selection precisely because, rather than being in the field, in the woods, or at the shore, he was a philosophe $d u$ cabinet. $)^{33}$

At least two major implications for philosophers follow from the above examples. First, thinking is not tied exclusively to language. Nonlinguistic forms of thinking thus demand acknowledgment and attentive study. Second, nonhuman animals are represented on each side of each of the oppositional divides - and so, of course, correlatively, are we humans. Thus not only are the divides suspect to begin with, but the axiological schemes that inform them are equally so.

In sum, the fundamental binary opposition that categorically separates humans and nonhumans and that progressively orders much of Western human thought is countermanded by the evidence. A hard and fast division, however much believed in or yearned for, flies in the face of historical facts which support evolutionary continuities, and in the face of nonhuman animal research studies that support the same continuities. It even appears to fly in the face of everyday Western practices and transactions, especially those having to do with humans' exploitatively grabbing whatever is at hand and not adequately devising strategies for the future. Indeed, perhaps "that is the best they can do."

\section{Notes}

${ }^{1}$ Aristotle, Categories $10.11 \mathrm{bl5}-13 \mathrm{~b} 35$.

${ }^{2}$ Daniel Dennett, Consciousness Explained (Boston: Little, Brown and Company, 1991), p. 178.

${ }^{3}$ Richard Dawkins, "Gaps in the Mind, " in The Great Ape Project $t_{2}$ eds. Paola Cavalieri and Peter Singer (London: Fourth Estate, 1993), pp. 80-87, p. 87.

4 These practices are those of chimpanzees, honeybees, certain groups of chimpanzees (specified and discussed in text below), primate nest-builders, male bower birds, and Japanese macaques, respectively. 
${ }^{5}$ Stephen Jay Gould, "So Near and Yet So Far," New York Review of Books 41/17 (October 20, 1994): 24-28, p. 27. Gould's article is a review of two books on Neandertals and addresses itself to the current Neandertal controversy.

${ }^{6}$ Stephen Jay Gould, "The Power of This View of Life," Natural History 103/6 (June 1994): 6-8, p. 8.

${ }^{7}$ Charles Darwin, The Descent of Man, and Selection in Relation to Sex (Princeton: Princeton University Press, 1981 [1871]); see especially Part I, chapter 2 . The phrase "persistent wholes" comes from the well-known 20th century evolutionary biologist J. S. Haldane, The Philosophical Basis of Biology (New York: Doubleday, Doran and Co., 1931), p. 13.

${ }^{8}$ Owen Flanagan, Consciousness Reconsidered (Cambridge: MIT Press/Bradford Books, 1992), p. 44. It should perhaps be noted that there appears to be a complete lack of awareness that behavior and not just hard-wiring, "mutant" or otherwise, is a driving force in evolution. The transition from water to land, for example, was accomplished by creatures - lobe- or flesh-finned fish - which, in addition to having lungs, had the possibility of using their fleshy paired fins to move on land, hence to crawl about to a new source of water if there was a drought. These fish evolved into the first amphibians precisely by exploiting behaviorally their anatomic-kinetic possibilities.

${ }^{9}$ Helena Curtis, Biology, 2nd edition (New York: Worth Publishers, 1975), p. 203.

${ }^{10}$ William T. Keeton and James L. Gould, Biological Science, 4th ed. (New York: W. W. Norton \& Co., 1986), p. 724 .

\section{${ }^{11}$ Flanagan, Consciousness Reconsidered, p. 43.}

${ }^{12}$ The phrase, of course, is Darwin's. See The Origin of Species ed. J. W. Burrow (Harmondsworth, Middlesex: Penguin Books, 1968 [1859]).

13 Jonathan Bennett attempts just such edification in his commentary on A. Whiten and R. W. Bryne's article "Tactical Perception in Primates" that appeared in The Behavioral and Brain Sciences (11 [1988]: 233-273). At the end of his response to the article (p. 247), Bennett writes, "Having described Whiten \& Bryne's problem situation in my own way, and expressed doubts about how far they have got with it, I want to add that I admire their grasp of what their problems are and of what would solve them. This is a useful and interesting paper, and I am glad to have a chance to try to push it further in its right direction." Philosophic hauteur relative to non-philosophers, especially those nonphilosophers working with nonhuman animals who bear a very close relationship to humans--e.g., chimpanzees, macaques, baboons, and so on-may be a way of dealing with an unacknowledged discomfort. Indeed, there is a sense in which the fundamental, axiologically uneven human/ nonhuman binary opposition is exemplified in Bennett's closing remarks to the primatologists.

14 The problem area concerns symbolic ascriptions (e.g., "symbolic behaviour" and related terms that are used to describe such things as tool-making, campsites, settlements, and so on). The terms "symbol" and "symbolic behaviour" are in particular need of fine, pains-taking clarification and elucidation. As it stands, they cover a multitude of confusions, the price of playing conceptually loose with language.

${ }^{15}$ Christopher Stringer and Clive Gamble, In Search of Neanderthals (London: Thames and Hudson, 1993), p. 203.

${ }^{16}$ For a discussion of all of these matters, see Maxine Sheets-Johnstone, The Roots of Thinking (Philadelphia: Temple University Press, 1990).

${ }^{17}$ Stringer and Gamble, Neanderthals, p. 207.

18 "They could certainly communicate, as can all social animals, and they no doubt spoke, albeit simply and probably slowly. We argue that the Neanderthals lacked complex spoken language because they did not need it.... [They did not have the social life to require it." (Ibid., p. 217). We might note how the stature of humans is maintained in corresponding terms in two other contexts. Daniel Dennett makes a similarly global claim about infant mentality. He states that in his view, consciousness "arises when there is work for it to do, and the preeminent work of consciousness is dependent on sophisticated language-using activities. " (Daniel Dennett, "Intentional Systems in Cognitive Ethnology: The 'Panglossian Paradigm" Defended," Behavioral and Brain Sciences 6 (1983): 343-390, p. 384). Being without language, infants, like nonhumans, are conceived as lacking the very bedrock of mental life: consciousness. Presumably, they are too busy learning how not to wet their pants to busy themselves with language or with a social life. With respect to the second context, a simple and "probably slow" speech is commensurate with a simple and "probably slow" person. Thus Stringer and Gamble's description is peculiarly reminiscent of the typical depiction of North American Indians in Hollywood Westerns who also spoke simply and slowly if at all. Were these Native American Indians human or were they subhuman, i.e., savages who could neither read nor write? Clearly, a lot hangs on language. The question is, is it too much?

I might note that a reviewer of this paper commented as follows: "Is it a fact that N's (sic) had language? What counts as lang. is itself very controversial." To my mind, what counts as language appears to depend upon who is doing the counting. Thus, the question, who is doing the counting? is as controversial as the question, what counts as language?

${ }^{19}$ The idea of there being a "mental essence" with respect to humanness comes (surprisingly) from Stephen Jay Gould 
in the course of his writing about the Neandertal controversy. See "So Near and Yet So Far," New York Review of Books 41/ 17 (October 20, 1994): 24-28, p. 28. In fact, there is much to criticize in his review article which favors Stringer and Gamble's position.

${ }^{20}$ W. C. McGrew, Chimpanzee Material Culture: Implications for Human Evolution (Cambridge: Cambridge University Press, 1992), p. 87. I should note that McGrew also points out that "Abundant examples now exist of the social transmission of acquired behaviour in groups of non-human animals" and that "objections in the earlier literature to biased anthropocentrism or simple reliance on anecdotes need no longer apply" (p. 72). I would like to point out too in response to a reviewer's concern-"Would help to say what you take culture to be"-that McGrew defines culture in very exacting terms according to eight specific criteria that allow "recognizing cultural acts in other species" (Ibid., p. 77). Finally, I might quote McGrew's comment concerning the reticence of anthropologists to acknowledge the evidence for culture in nonhuman animals--since the same reticence might well be found among philosophers. McGrew writes that "The overall impression is that until recently anthropologists either long ignored the evidence for nonhuman culture, erected ad hominem criteria which avoided taking the phenomenon seriously or, having considered the problem felt it necessary to move the goal-posts" (Ibid., p. 73).

${ }^{21}$ Kanzi was born (1980) and reared at the Georgia State University Language Research Center.

${ }^{22}$ See Alvin M. Liberman and Ignatius G. Mattingly, "The Motor Theory of Speech Perception Revised," Cognition 21 (1985): 1-36.

${ }^{23}$ Ibid., p. 26.

${ }^{24}$ See Sue Savage-Rumbaugh and Roger Lewin, Kanzi (New York: John Wiley \& Sons, 1994), 169-170; and Bonobo People, Georgia State University Language Research Center video (footage by NHK of Japan). See also E. Sue SavageRumbaugh, Jeannine Murphy, Rose A. Sevcik, Karen E. Brakke, Shelly L. Williams, Duane M. Rumbaugh, Language Comprehension in Ape and Child (Monographs of the Society for Research in Child Development 58/3-4 [1993]) (Chicago: University of Chicago Press, 1993).

${ }^{25}$ A reviewer of this paper commented, "Wouldn't hurt to say what you mean by thinking" and further, wondered with respect to thinking and reasoning, "How are these different?" I would answer generally that one can think without reasoning but one cannot reason without thinking. I would give as examples the following:

1. I am thirsty. I think: "I'll get a drink."

2. I can think of my vacation last year and about going to the same place again this year without reasoning.
3. Thinking via analogies is not reasoning

4. Thinking about a problem, I suddenly find an answerwithout reasoning.

5. When asked to give reasons for my behavior, I think about what motivates my behavior.

6. When reasoning with respect to developing an argument, I think about various facets of the issue.

${ }^{26}$ Bernd Heinrich, “A Birdbrain Nevermore," Natural History 102/10 (October 1993): 51-56, pp. 53-54.

${ }^{27}$ Ibid., p. 55.

${ }^{28}$ Sextus Empiricus, Outlines of Pyrrhonism, trans. R. G. Bury (Buffalo: Prometheus Books, 1990), p. 36. In more detailed explanation, Sextus writes that the dog (according to Chrysippus) "makes use of the fifth complex indemonstrable syllogism... [f]or, says the old writer [Chrysippus], the dog implicitly reasons thus: "The creature went either by this road or by that, or by the other: but it did not go by this road or by that: therefore it went by the other'" (Ibid.).

${ }^{29}$ See note 9.

${ }^{30}$ Charles Darwin, The Descent of Man, p. 48. (The second example is also given on p. 48.)

${ }^{31}$ Ibid.

32 Ibid., p. 46

${ }^{33}$ See Maxine Sheets-Johnstone, "Why Lamarck Did Not Discover the Principle of Natural Selection," Journal of the History of Biology 15/3 (Fall 1982): 443-465.

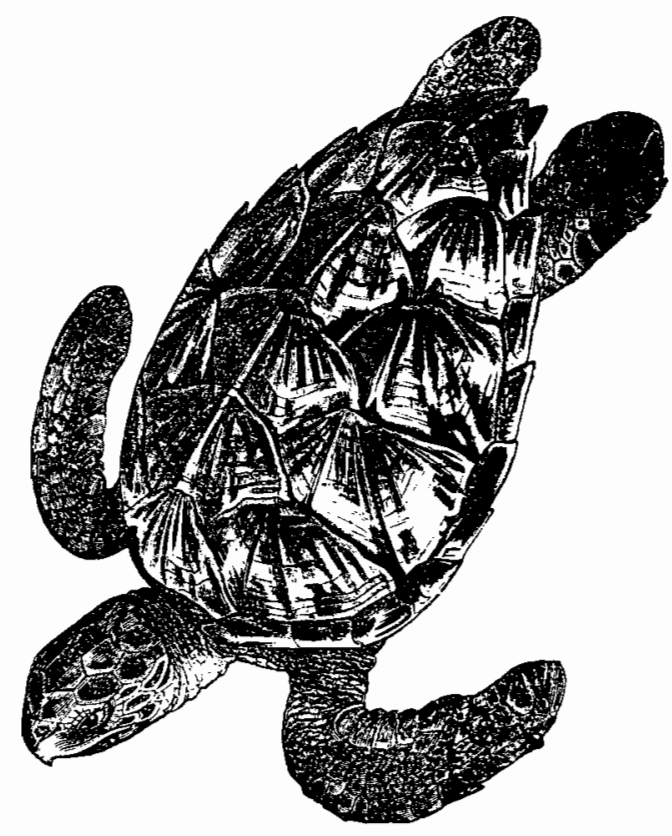

